\title{
Vergi Mizanından BOBİ FRS'ye Dönüşüm Kayıtlarının Yapılması Ve Finansal Tablolar Çıkarılmasına Dair Bütünsel Bir Uygulama*
}

\section{$\ddot{O Z Z E T}$}

Büyük ve Orta Boy İșletmeler için Finansal Raporlama Standartları (BOBİ FRS) Kamu Gözetimi Muhasebe ve Denetim Standartları Kurumu (KGK) tarafindan yayımlanarak 1.1.2018 tarihinden itibaren yürürlüğe girmiştir. KGK Finansal Raporlama Standartlarına Uygun Hesap Planı Taslağını 25.12.2018 tarihinde açıklamıștır. Bu çalışmada vergi mizanindan hareketle BOBI FRS' ye dönüşüm kayıtlarının nasıl yapılacağı ve bunun sonucunda finansal tabloların çıkarılmasına dair bütünsel bir uygulama örneği geliştirilmektedir. Uygulama örneğinde öncelikle oluşturulan vergi mizanına ait verilerin kullanılmasıyla yıllık kurumlar vergisi beyannamesine ek olması gereken finansal tablolar (bilanço ve gelir tablosu) düzenlenmekte, ikinci aşamada vergi mizanından BOBI FRS' ye geçişte gerekli olan veriler oluşturularak BOBI FRS' ye dönüșüm kayıtları yapılmakta ve son aşamasında ise BOBİ FRS' ye uygun bilanço ve kar/zarar tablosu çıkarılarak kapanış kayıtları yapılmaktadır. Bütünsel uygulama örneğinde muhasebe kayıtları ve finansal tabloların olușturulmasında KGK tarafindan yayınlanan FRS' ye Uygun Hesap Planı Taslağında yer alan hesap kodları ve adları kullanılmaktadır.

\section{A Complete Practice For Recognizing Transformation Registrations From Tax} Balance To BOBI Frs And Forming Finnancial Statements

\section{ABSTRACT}

Financial Reporting Standards for Large and Medium Sized Enterprises (BOBI FRS) were published by the Public Oversight Accounting and Auditing Standards Authority (POA) and entered into force on 1.1.2018. The POA has announced the Draft Chart of Accounts in accordance with the Financial Reporting Standards. In this study, a complete application example is developed on how to make the transformation records to BOBI FRS based on the tax balance and consequently the preparation of financial statements. In the application example, firstly, by using the data of the tax balance created, it is prepared in the financial statements (balance sheet and income statement) which should be annexed to the annual corporate tax return. In the second stage, the necessary data for the transition from tax balance to BOBI FRS are created and the conversion records are made to BOBI FRS and in the last stage, the balance sheet and profit / loss statement in accordance with BOBI FRS are issued and closing records are made. balance sheet and profit / loss statement in accordance with BOBI FRS are issued and closing records are made. In the complete application example, accounting codes and names in the FRS Draft Account Plan published by POA are used in the creation of accounting records and financial statements.

Keywords: Tax Balance, IAS/IFRS, Financial Statements

Jel Classification: $H$ 29, $M$ 41, M 42, $M 49$

* Makale Gönderim Tarihi: 27.06.2019,Makale Kabul Tarihi: 17.07.2019,Makale Türü: Örnek Olay Çalışması

* Doç. Dr., Maltepe Üniversitesi, serefdemir@maltepe.edu.tr, ORCID ID: 6792120 


\section{GíRiș}

Kamu Gözetimi Kurumu tarafindan açıklandığı üzere "Bağımsız Denetime Tabi Şirketlerin Belirlenmesine Dair Karar" uyarınca bağımsız denetime tabi olup zorunlu veya isteğe bağlı olarak TFRS uygulayan işletmeler, finansal tabloların finansal tablo örneklerine göre hazırlamakla yükümlüdürler. TFRS' ye göre finansal tablolarını hazırlayanlar muhasebe, defter ve kayıtları ile TFRS' ye göre hazırlanmış finansal tablolar arasındaki ilişkiyi kurmak, bir sonraki yıl finansal tablolarının sağlıklı bir şekilde hazırlanmasını sağlamak ve TFRS' ye göre hazırlayacakları finansal tablolara ulaşmak için yapacakları kayıtları göstermek üzere, 6102 sayılı Türk Ticaret Kanunun 64 ve 82 nci maddeleri çerçevesinde, varsa gerekli düzeltme işlemlerini ticari defterlerinden ayrı bir şekilde kaydedip saklarlar ve gerektiğinde ibraz ederler.

Öte yandan Türkiye'de ağırlıklı olarak vergi muhasebesi tutulmakta ve buna göre finansal tablolar çıkarılmaktadır. Vergi Usul Kanunu, TMS/TFRS ve Büyük ve Orta Ölçekli İşletmeler İçin Finansal Raporlama Standartları (BOBİ FRS) arasında önemli derecede sinıflandırma ve değerleme farklılıkları bulunmaktadır. Dolayısıyla gerekli hesapların açılması ve uygun değerleme ölçüsü kullanılarak değerlemeye tabi tutulması ve finansal tablolarda ait olduğu sınıflandırma ve değerleme ölçüsü ile yer alması gerekmektedir. Bu çalışmada vergi mizanından hareketle BOBİ FRS' ye uygun dönüştürme kayıtları ele alınmakta ve bu kayıtlar neticesinde finansal tablolar çıkarılmaktadır. Örnek uygulamada KGK tarafindan taslak olarak yayınlanan TFRS' ye uygun hesap planı kullanılmaktadır. Hesap Planı taslak olarak kalsa dahi uygulamada fayda sağlayacak içerikle hazırlanmıştır ve yol gösterici niteliktedir. BOBİ FRS ve Vergi Usul Kanunu arasındaki geçici özellik taşıyan değerleme farklılıkları için Ertelenmiş Vergi Varlığı, Ertelenmiş Vergi Yükümlülüğü adı altında bilanço hesapları kullanılmaktadır. Öz kaynakları ilgilendiren değerleme farklılıklarının vergi etkileri ilgili Standartta yer alan değerleme hükmüne bağlı olarak "Kar veya Zararda Yeniden Sınıflandırılmayacak Öz kaynaklarda Kaydedilen Birikmiş Gelirlere (Giderlere) İlişkin Vergi" hesabına ya da "Kar veya Zararda Yeniden Sınıflandırılacak Öz kaynaklarda Kaydedilen Birikmiş Gelirlere (Giderlere) İlişkin Vergi" hesabına kaydedilmektedir. Değerleme farklılıklarının sonuç hesaplarını farklılaştırması halinde ise vergi etkisi "Sürdürülen Faaliyetler Ertelenmiş Vergi Gelir-Gider Etkisi (+/-)" hesabı ile kar zarara yansıtılmaktadır. Bu çalışmada vergi mizanından hareketle TFRS' ye dönüşüm kayıtlarının yapılması ve finansal tabloların çıkarılmasına dair bütünsel bir uygulama örneğinde vergi mizanına ait veriler kullanılarak vergi beyannamesine ek olması gereken bilanço ve gelir tablosu çıkarıldıktan sonra BOBİ FRS' ye dönüşüm kayıtları yapılmakta ve nihayetinde BOBİ FRS' ye uygun bilanço ve kar/zarar tablosu çıkarılmaktadır.

\section{VERGİ BILLANÇOSU VE GELIIR TABLOSUNUN ÇIKARILMASI VE KURUMLAR VERGISİ BEYANI}

29 Temmuz 2017 tarih ve 30138 mükerrer sayllı Resmi Gazete' de "Büyük ve Orta Boy İşletmeler İçin Finansal Raporlama Standardı Hakkında Tebliğ (Sıra No: 56)" yayımlanmış olup, bu Tebliğ ile bağımsız denetime tabi olup Türkiye Finansal Raporlama 
Standartlarını uygulamayan işletmelerin münferit ve konsolide finansal tablolarının hazırlanmasında Büyük ve Orta Boy İşletmeler için Finansal Raporlama Standardının (BOBİ FRS) uygulanması 1/1/2018 tarihinden itibaren zorunlu hale gelmiştir. Vergi Usul Kanununa dayanılarak çıkarılan Muhasebe Sistemi Uygulama Genel Tebliğlerinde öncelikli amacın, mükelleflerin vergi karşısındaki durumunun gösterilmesi olması sebebiyle finansal tabloların gerçeğe uygun, ihtiyaca uygun ve karşılaştırılabilir bilgi sağlama amacından uzaklaştı̆̆ görüldüğünden, bağımsız denetime tabi olup TFRS uygulamayan şirketlerin Türk Ticaret Kanunu uyarınca genel kurullarına sunulacak finansal tablolarının hazırlanmasinda esas alınacak finansal raporlama çerçevesi Kamu Gözetimi Muhasebe ve Denetim Standartları Kurumu tarafindan BOBİ FRS olarak belirlenmiş̧ir.

Vergi Usul Kanunu gereklerini karşılayan Tekdüzen Hesap Planı ile TMS/TFRS ve Büyük ve Orta Ölçekli İşletmeler İçin Finansal Raporlama Standartları (BOBİ FRS) gereklerini karşılayan KGK Taslak Hesap Planı arasındaki çok sayıda farklılık bulunmaktadır. VUK mizanından BOBİ FRS' ye dönüşümde söz konusu farklılıkların giderilmesi için BOBİ FRS' ye uygun hesapların açılması ve finansal tablolarda ait olduğu sınıflandırma ve değerleme ölçüsü ile yer alması gerekmektedir. Vergi mizanından BOBİ FRS' ye dönüşümün amaçlandığı bu çalışmada öncelikle vergi mizanından hareketle kurumlar vergisi beyannamesinin ekinde yer alması gereken mali tablolar çıkarılmakta ve yıllık kurumlar vergisi beyannamesi hazırlanmaktadır. Aşağıda bir şirkete ait (Birlik A.Ş.) vergi mizanı yer almakta olup, söz konusu mizandan hareketle kurumlar vergisi beyannamesine ek olmas1 gereken bilanço, gelir tablosu çıkarılmakta ve vergi beyannamesi hazırlanmakta ve vergi muhasebesi kapanış kayıtları yapılmaktadır.

\begin{tabular}{|c|c|c|c|}
\hline \multicolumn{4}{|c|}{ BİRLIK A.Ş. VERGİ MİZANI } \\
\hline HES.K. & HESAP ADI & BORÇ B. & ALAC. B. \\
\hline 100 & KASA & 100.000 & \\
\hline 101 & ALINAN ÇEKLER & 2.000 .000 & \\
\hline 102 & BANKALAR & 700.000 & \\
\hline 103 & VERİLEN ÇEK ve ÖDEME EMRİ (-) & & 700.000 \\
\hline 108 & DİĞER HAZIR DEĞERLER & 500.000 & \\
\hline 110 & HİSSE SENETLERİ & 300.000 & \\
\hline 111 & ÖZEL KESİM TAHVİL SNT.VE BONO. & 0 & \\
\hline 112 & KAMU KESIMII TAHVIL SNT.VE BONO & 0 & \\
\hline 120 & ALICILAR & 10.000 .000 & \\
\hline 121 & ALACAK SENETLERİ & $\begin{array}{l}5.000 .000 \\
\end{array}$ & \\
\hline 128 & ŞÜPHELİ TİCARİ ALACAKLAR & 1.000 .000 & \\
\hline 129 & ŞÜPHELİ TİC.AL. KARŞIĞI (-) & 0 & 0 \\
\hline 153 & TİCARİ MALLAR & 3.000 .000 & \\
\hline 181 & GELIR TAHAKKUKLARI & 100.000 & \\
\hline 190 & DEVREDEN KATMA DEĞER VERGİİ & 120.000 & \\
\hline 191 & İNDİRILECEK KDV & 0 & 0 \\
\hline 250 & ARAZİ VE ARSALAR & 3.000 .000 & \\
\hline 252 & BİNALAR & 7.000 .000 & \\
\hline
\end{tabular}




\begin{tabular}{|c|c|c|c|}
\hline 253 & ||TESIS MAKİNE VE CIHAZLAR & 1.000 .000 & \\
\hline 254 & TAŞITLAR & 500.000 & \\
\hline 255 & DEMİRBAŞLAR & 300.000 & \\
\hline 256 & DİĞER MADDİ DURAN VARLIKLAR & 0 & 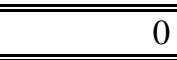 \\
\hline 257 & BİRİKMISŞ AMORTİSMANLAR (-) & & 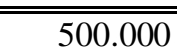 \\
\hline 262 & KURULUŞ VE ÖRGÜTLENME GIDER. & 300.000 & \\
\hline 263 & ARAŞTIRMA VE GELIŞTİRME GIDER. & 100.000 & \\
\hline 264 & ÖZEL MALIYETLER & 70.000 & \\
\hline 268 & BİRİKMİŞ AMORTİSMANLAR (-) & & 994.000 \\
\hline 300 & BANKA KREDİLERİ & & 15.000 .000 \\
\hline 320 & SATICILAR & & 1.600 .000 \\
\hline 360 & ÖDENECEK VERGİ VE FONLAR & & 100.000 \\
\hline 361 & ÖDENECEK SOS. GÜV. KESİNTİLERİ & & 60.000 \\
\hline 370 & DÖN.KARI VER.VE DİĞ.YÜK.KARŞ. & & \\
\hline 371 & DÖN.KAR.PEŞ.ÖD.VER.VE YÜK (-) & 200.000 & \\
\hline$\overline{500}$ & SERMAYE & & 15.836 .000 \\
\hline 590 & DÖNEM NET KARI & & \\
\hline 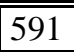 & DÖNEM NET ZARARI (-) & & \\
\hline 600 & YURT İÇi SATIŞLAR & & 10.000 .000 \\
\hline 621 & SATILAN TİC.MALLAR MALIYYETI(-) & 7.000 .000 & \\
\hline 630 & ARAŞTIRMA VE GELIŞTİRME GİD(-) & & \\
\hline 631 & PAZARLAMA SAT.VE DAĞ.GİD. (-) & 500.000 & \\
\hline 632 & GENEL YÖNETIM GIDERLERİ (-) & 200.000 & \\
\hline 640 & İŞTİRAKLERDEN TEMETTÜ GELİR. & & 1.000 .000 \\
\hline 642 & FAİZ GELİRLERİ & & 100.000 \\
\hline 679 & DİĞ.OLAĞANDIŞI GELİR VE KARLAR & & \\
\hline 680 & ÇALIŞMAYAN KISIM GID.VE ZAR(-) & 2.000 .000 & \\
\hline 681 & ÖNCEKİ DÖN.GID.VE ZARARLARI(-) & & \\
\hline 689 & DİĞER O.DIŞI GIID.VE ZARAR.(-) & & \\
\hline 690 & DÖNEM KARI VEYA ZARARI & & \\
\hline 691 & D.K.VER.VE DİĞ.YAS.YÜK.KAR.(-) & & \\
\hline \multirow[t]{2}{*}{ 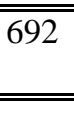 } & DÖNEM NET KARI VEYA ZARARI & & \\
\hline & TOPLAM & 44.990.000 & 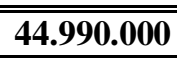 \\
\hline
\end{tabular}

Yukarıdaki verilere göre Birlik A.Ş. nin VUK Bilanço ve Gelir Tablosu ile Kurumlar Vergisi Beyannamesi aşağıdadır. Kurumlar Vergisi Oranı \% 20 olarak alınmıştır.

\begin{tabular}{|l|r|r|}
\hline 1 DÖNEN VARLIKLAR & & $\mathbf{2 2 . 1 2 0 . 0 0 0}$ \\
\hline 10 HAZIR DEĞERLER & & 2.600 .000 \\
\hline 100 KASA & 100.000 & \\
\hline 101 ALINAN ÇEKLER & 2.000 .000 & \\
\hline 102 BANKALAR & 700.000 & \\
\hline 103 VERİLEN ÇEKLER VE ÖDEME EMİRLERİ (-) & $5.000 .000)$ & \\
\hline 108 DİĞER HAZIR DEĞERLER & & $\mathbf{3 0 0 . 0 0 0}$ \\
\hline 11 MENKUL KIYMETLER & & \\
\hline
\end{tabular}




\begin{tabular}{|c|c|c|}
\hline 110 HISSSE SENETLERİ & 300.000 & \\
\hline 12 TİCARİ ALACAKLAR & & 16.000 .000 \\
\hline 120 ALICILAR & 10.000 .000 & \\
\hline 121 ALACAK SENETLERİ & 5.000 .000 & \\
\hline 128 ŞÜPHELİ TİCARİ ALACAKLAR & 1.000 .000 & \\
\hline 129 ŞÜPHELİ TİCARİ ALACAKLAR KARŞILIĞI (-) & 0 & \\
\hline 15 STOKLAR & & 3.000 .000 \\
\hline 153 TİCARİ MALLAR & 3.000 .000 & \\
\hline $\begin{array}{l}18 \text { GELECEK AYLARA AİT GİDERLER VE GELİR } \\
\text { TAHAKKUKLARI }\end{array}$ & & 100.000 \\
\hline 181 GELİR TAHAKKUKLARI & 100.000 & \\
\hline 19 DİĞER DÖNEN VARLIKLAR & & 120.000 \\
\hline 190 DEVREDEN KDV & 120.000 & \\
\hline DURAN VARLIKLAR & & 11.676 .000 \\
\hline 25 MADDİ DURAN VARLIKLAR & & 11.300 .000 \\
\hline 250. ARAZI VE ARSALAR & 3.000 .000 & \\
\hline 252. BİNALAR & 7.000 .000 & \\
\hline 253. TESIS, MAKINNE VE CIHAZLAR & 1.000 .000 & \\
\hline 254. TAŞITLAR & 500.000 & \\
\hline 255. DEMİRBAŞLAR & 300.000 & \\
\hline 257. BİRİKMISS AMORTİSMANLAR (-) & $(500.000)$ & \\
\hline 26 MADDİ OLMAYAN DURAN VARLIKLAR & & 376.000 \\
\hline 262. KURULUŞ VE ÖRGÜTLENME GIDERLERİ & 300.000 & \\
\hline 263. ARAŞTIRMA VE GELIŞTİRME GİDERLERİ & 100.000 & \\
\hline 264. ÖZEL MALIYYTLER & 70.000 & \\
\hline 268. BİRİKMISS AMORTİSMANLAR (-) & $(94.000)$ & \\
\hline TOPLAM VARLIKLAR & & 33.796 .000 \\
\hline
\end{tabular}

\begin{tabular}{|l|r|r|}
\hline 3 KISA VADELI YABANCI KAYNAKLAR & & $\mathbf{1 6 . 6 2 0 . 0 0 0}$ \\
\hline 30 MALİ BORÇLAR & & $\mathbf{1 5 . 0 0 0 . 0 0 0}$ \\
\hline 300. BANKA KREDİLERİ & 15.000 .000 & \\
\hline 32 TİCARİ BORÇLAR & & $\mathbf{1 . 6 0 0 . 0 0 0}$ \\
\hline 320. SATICILAR & & \\
\hline 36 ÖDENECEK VERGI VE DİĞER YÜKÜMLÜLÜKLER & 1.600 .000 & $\mathbf{1 6 0 . 0 0 0}$ \\
\hline 360. ÖDENECEK VERGİ VE FONLAR & 60.000 & \\
\hline 361. ÖDENECEK SOSYAL GÜVENLİK KESİNTİLERİ & & $\mathbf{( 1 4 0 . 0 0 0 )}$ \\
\hline 37 BORÇ VE GİDER KARŞILIKLARI & 60.000 & \\
\hline $\begin{array}{l}\text { 370. DÖNEM KÂRI VERGİ VE DİĞER YASAL YÜKÜMLÜLÜK } \\
\text { KARŞILIKLARI }\end{array}$ & $(200.000)$ & \\
\hline $\begin{array}{l}\text { 371. DÖNEM KÂRININ PEŞİN ÖDENEN VERGİ VE DİĞER } \\
\text { YÜKÜMLÜLÜKLERİ (-) }\end{array}$ & & $\mathbf{1 7 . 1 7 6 . 0 0 0}$ \\
\hline 5 ÖZ KAYNAKLAR & & $\mathbf{1 5 . 8 3 6 . 0 0 0}$ \\
\hline 50 ÖDENMIŞ SERMAYE & 15.836 .000 & \\
\hline 500. SERMAYE & & $\mathbf{1 . 3 4 0 . 0 0 0}$ \\
\hline 59 DÖNEM NET KÂRI (ZARARI) & 1.340 .000 & \\
\hline 590. DÖNEM NET KÂRI & & $\mathbf{3 3 . 7 9 6 . 0 0 0}$ \\
\hline TOPLAM KAYNAKLAR & & \\
\hline
\end{tabular}




\begin{tabular}{|c|c|c|}
\hline 6 GELİR TABLOSU HESAPLARI & & \\
\hline 60 BRÜT SATIŞLAR & & 10.000 .000 \\
\hline 600. YURTİÇİ SATIŞLAR & 10.000 .000 & \\
\hline 62 SATIŞLARIN MALIYYTİ (-) & & (7.000.000) \\
\hline 621. SATILAN TİCARİ MALLAR MALIYYETİ (-) & $(7.000 .000)$ & \\
\hline 63 FAALIYYET GIDERLERİ (-) & & 2.500 .000 \\
\hline 631. PAZARLAMA SATIŞ VE DAĞITIM GIDDERLERİ & $(2.000 .000)$ & \\
\hline 632. GENEL YÖNETİM GİDERLERİ (-) & $(500.000)$ & \\
\hline 64 DİĞER FAALIYYETLERDEN OLAĞAN GELİR VE KÂRLAR & & $\mathbf{1 . 1 0 0 . 0 0 0}$ \\
\hline 640. İŞTİRAKLERDEN TEMETTÜ GELİRLERI & 1.000 .000 & \\
\hline 642. FAİZ GELİRLERİ & 100.000 & \\
\hline 68 OLAĞANDIŞI GIDER VE ZARARLAR (-) & & $(2.000 .000)$ \\
\hline 680. ÇALIŞMAYAN KISIM GIDER VE ZARARLARI (-) & $(2.000 .000)$ & \\
\hline 69 DÖNEM NET KÂRI (ZARARI) & & 1.340.000 \\
\hline 690. DÖNEM KÂRI VEYA ZARARI & 1.400 .000 & \\
\hline $\begin{array}{l}\text { 691. DÖNEM KÂRI VERGİ VE DİĞER YASAL YÜKÜMLÜLÜK } \\
\text { KARŞILIKLARI (-) }\end{array}$ & $(60.000)$ & \\
\hline 692. DÖNEM NET KÂRI VEYA ZARARI & 1.340 .000 & \\
\hline
\end{tabular}

\begin{tabular}{|lc|}
\hline Yıllık Kurumlar Vergisi Beyannamesi \\
\hline 1. Ticari Bilânço Karı \\
\hline 2. Kanunen Kabul Edilmeyen Giderler (+) \\
\hline 3. Kar ve İlaveler Toplamı (1+2) \\
\hline 4. Zarar Olsa Dahi İndirilecek İstisnalar (KV Bey. 33-46’ncı satırlar) (-) \\
\hline (İştirak Kazançları istisnası 1.400 .000 \\
\hline 5. Zarar Olsa Dahi İndirilecek İndirimler (KV Beyannamesi 47'nci satır) (-) \\
\hline 6. Cari Yıla Ait Zarar İstisna ve İndirimler Toplamı (4+5) \\
\hline 7. Kar (3-6) \\
\hline 8. Geçmiş yıl zararları (-) \\
\hline 9. İndirime Esas Tutar \\
\hline 10. Kazancın bulunması halinde indirilecek istisnalar ve indirimler \\
\hline (AR-GE indirimi 100.000) \\
\hline 11. Dönem Safi Kurum Kazancı (Matrah) (9-10) \\
\hline 12. Hesaplanan Kurumlar Vergisi (Kurumlar Vergisi \% 20) \\
\hline
\end{tabular}

\section{Vergi Muhasebesi Dönem Sonu Kapanış Kayıtları:}

31.12.2019

690 Dönem Kar Zararı

691 Dönem Karı Vergi ve Diğer Yasal

60.000

Yükümlülük Karşılıkları

692 Dönem Net Kar Zararı

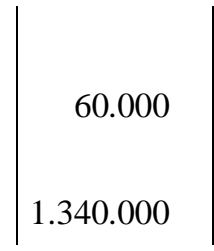

31.12 .2019

692 Dönem Net Kar Zararı

590 Dönem Net Kar Zararı 
31.12.2019

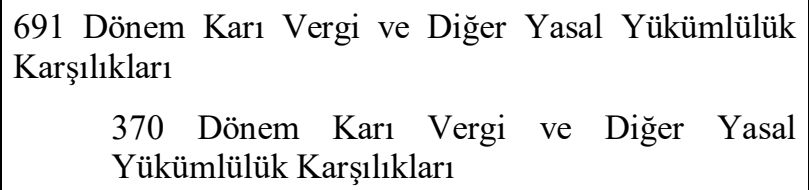

60.000

60.000

Örnek uygulama verilerine göre "Birlik A.Ş." Bağımsız denetime tabi bir firmadır ve dönem sonunda finansal tabloların BOBİ FRS uyumlu olarak hazırlamak istemektedir. VUK Mizandan BOBİ FRS' ye çeviri verileri şirket yetkilileri ile birlikte aşağıdaki gibi tespit edilmiştir. Söz konusu veriler kullanılarak BOBİ FRS dönüşüm kayıtları yapılmak suretiyle BOBİ FRS' ye uygun bilanço ve kar zarar cetveli çıkarılacaktır. Hesap adı ve kodu olarak KGK tarafından açıklanan BOBİ FRS' ye Uygun Taslak Hesap Planı kullanılacaktır.

\section{VUK MIZANDAN BOBİ FRS'YE DÖNÜŞÜM VERILERİ VE KAYITLARI}

Birlik A.Ş. Tek Düzen Hesap Planı, Muhasebe Sistemi Uygulama Genel Tebliğleri ve nihayetinde Vergi mevzuatı kapsamında muhasebe kayıtları neticesinde elde ettiği mizan bilgileri 31.12.2019 tarihi itibariyle, dönem sonu envanter ve ilave bilgilere dair açıklamalar aşağıdaki gibidir. Fonksiyonel para birimi ve raporlama para birimi TL'dir.

1) Kasa hesabının bakiyesi 100.000 TL olup fiili envanter uyumu sağlanmıştır. Kasada mevcut yabanc1 para bulunmamaktadır.

2) Bankalarda bulunan 700.000 TL vadeli mevduat için döneme isabet eden 100.000 TL faiz tahakkuk ettirilmiştir. Banka mutabakatları sağlanmıştır. Etkin Faiz hesaplamasında döneme isabet eden faiz tahakkuku 90.000 TL'dir. Bankalarda döviz hesab1 bulunmamaktadır.

3) Alınan Çeklerin bakiyesi 2.000.000 TL olup ortalama vade 370 gündür. Yapılan hesaplamada alınan çeklerin içerisinde 300.000 TL gerçekleşmemiş faiz bulunduğu anlaşılmıştır.

4) Verilen Çeklerin bakiyesi 700.000 TL olup ortalama vade 370 gün olarak hesaplanmıştır. Yapılan hesaplamada verilen çeklerin içerisinde 100.000 TL gerçekleşmemiş faiz bulunduğu anlaşılmıştır.

5) Diğer hazır değerler kredi kartlarından alacaklar toplam 500.000 TL'dir. Söz konusu alacaklar yurt içi satışlardan kaynaklanmaktadır. Kredi kartı alacaklarının içerisinde 20.000 TL gerçekleşmemiş faiz bulunduğu hesaplanmıştır.

6) Şirket portföyünde tahvil ve bono bulunmamaktadır

7) Şirket 6 ay sonrası için 8 TL'den 100.000 Euro forward kontrata girmiştir. Başlangıç maliyeti bulunmamaktadır. 
8) Şirket portföyünde uzun vadede değer artış kazancı sağlamak üzere 300.000 TL tutarında hisse senedi bulunmaktadır. Hisse senetleri BIST' te işlem görmektedir. Gerçeğe Uygun Değer 800.000 TL'dir.

9) Şirketin dava ve icra safhasında olmaması nedeniyle VUK kapsamında şüpheli alacak karşılığı ayırmadığı, sadece alıcılar hesabından şüpheli alacak hesabına aktardığ 1.000.000 TL alacağının, bir müşterisinden $300.000 \mathrm{TL}$ alacak kısmı için ilgili şirketin konkordato hazırlığında olduğu anlaşılmıştır.

10) Şirketin alacaklarını yaşlandırması nedeniyle şüpheli alacak karşılığ1 ayrılması gereken alacak tutarı 200.000 TL olarak hesaplanmıştır.

11) Şirketin garanti gider karşılıkları 700.000 TL olarak hesaplanmıştır.

12) Kıdem tazminat karşılıkları 500.000 TL, birikmiş izin karş1lıkları 100.000 TL'dir.

13) Esas faaliyetlerden alacaklar 10.000.000 TL'dir. Ortalama alacak vadesi 370 gün olarak hesaplanmıştır. Söz konusu alacakların 1.000.000 TL'si gerçekleşmemiş faiz tutarıdır.

14) Stokların fiili ve kaydi envanter uyumu sağlanmıştır. Ticari mal stokları 3.000 .000 TL olup, bu tutarın içerisinde 750.000 TL gerçekleşmemiş faiz bulunmaktadır. Stoklar (ticari mallar) ortalama 370 gün vadeli olarak satın alınmaktadır.

15) Bir kısım stokların maliyet bedeli 500.000 TL, tahmini satış fiyatı 450.000 TL, tahmini tamamlama maliyeti $40.000 \mathrm{TL}$ ve tahmini satış giderleri $10.000 \mathrm{TL}$ hesaplanmıştır.

16) Maddi duran varlıklarda yer alan binaların defter değeri 7.000.000 TL'dir. $\mathrm{Bu}$ tutarın 1.000.000 TL'lik kısmı olan binalar için satış kararı alınmış ve satış görüşmelerine başlanmıştır. 2.000.000 TL'lik kısım ise kiraya verilmiştir. Kiraya verilen binaların gerçeğe uygun değer tespiti konusunda yönetim yüksek maliyete katlanmak istememektedir.

17) Maddi duran varlıklarda yer alan arsalar (3.000.000 TL) yatırım amaçlı gayrimenkuller olarak değerlendirilecek olup, yeniden değerleme modeli seçilmiştir. Değerleme raporuna göre değeri 5.000.000 TL olarak hesaplanmıştır.

18) Maddi duran varlıklarda yer alan 1.000.000 TL değerindeki binaların arsa payının değeri 600.000 TL'dir.

19) Makineler 1.000 .000 TL olup, 600.000 TL birikmiş amortismanları bulunmaktadır. Satış maliyetleri düşülmüş gerçeğe uygun değer $350.000 \mathrm{TL}$, kullanım değeri 300.000 TL olarak hesaplanmıştır.

20) Demirbaşlar için yeniden değerleme modeli seçilmiş olup 300.000 TL defter değeri bulunan demirbaşlar için gerçeğe uygun değer 500.000 TL olarak belirlenmiştir.

21) Binalardan TFRS kapsamında arsa ve arazilere aktarılan 600.000 TL için VUK' a göre binalar kapsamında 12.000 TL amortisman gideri ayrılarak genel yönetim giderlerine yansitılmıştır. 
22) 300.000 TL kuruluş ve örgütlenme gideri VUK' a uygun olarak aktifleştirilmiş ve $\% 20$ oranında itfa edilmiştir.

23) Kiracı olarak yönetim binasına özel maliyet niteliğinde yapılan (asansör, radyatör) harcamaları 70.000 TL'dir. Aktifleștirilen özel maliyetler için \% 20 oranında itfa payı ayrılmıştır.

24) VUK için ayrılan amortismanlar BOBİ FRS' ye göre ayrılacak amortismanlardan 100.000 TL fazladır.

25) Satışlar 10.000.000 TL olup 2.000.000 TL vade farkı (370 gün) içermektedir.

26) Satılan ticari malların maliyeti 7.000.000 TL olup, bu tutarın içerisinde 1.400 .000 TL (370 gün) vade farkı bulunmaktadır.

27) 15.000.000 TL banka kredisi alınmıştır.

Yukarıdaki verilere göre VUK Mizandan TFRS' ye dönüșüm kayıtları ve açılamalar așağıdaki gibidir:

1- BOBİ FRS için "100 Kasa" hesabı "Hazır Değerler" hesap grubu olarak değil "10 Nakit ve Nakit Benzerleri” hesap grubunda "100 Nakit Kasası" hesabı olarak yer alacaktır. Vergi mizanından BOBİ FRS' ye dönüşümünde aşağıda yer alan düzeltme kaydı yapılır.

31.12.2019

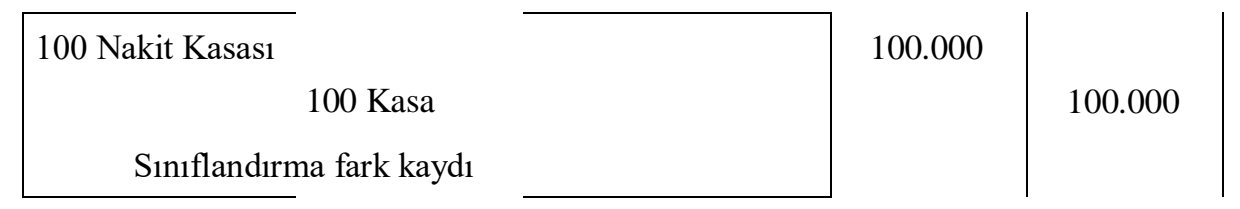

2- Vergi mizanında vadeli mevduat için dönem sonunda aşağıdaki kayıtta olduğu gibi faiz tahakkuk ettirilmektedir.

31.1.2019

181 Gelir Tahakkukları

642 Faiz Gelirleri

Döneme isabet eden faiz tahakkuku

\begin{tabular}{l|l}
100.000 & 100.000
\end{tabular}

BOBİ FRS ve TMS/TFRS' de itfa edilmiş maliyet bedeli ile değerleme nedeniyle 181 Gelir Tahakkukları hesabı kullanılmamaktadır. Ayrıca etkin faiz hesaplanması nedeniyle faiz tutarı farklı olmaktadır. Verilere göre VUK gereğince faiz geliri 100.000 TL iken etkin faiz hesaplanması sonucunda $90.000 \mathrm{TL}$ faiz tahakkuku çıkmaktadır. Faiz tahakkuku $181 \mathrm{Gelir}$ Tahakkukları hesabı yerine 102 Bankalar hesabına yapılacaktır. (100.000-90.000=) 10.000 TL faiz geliri azaltılacak ve vadeli hesap olması nedeniyle de 102 Bankalar hesab1 yerine 115 Bankalardaki Vadeli Mevduat hesabı kullanılacaktır. 642 Faiz Gelirleri hesabı yerine 660 Mevduat Faiz Gelirleri hesabı taslak hesap planında yer almaktadır. 
31.12.2019

\begin{tabular}{|c|c|c|}
\hline $\begin{array}{c}102 \text { Bankalar } \\
\text { Sinıflandırma fark kaydı }\end{array}$ & 100.000 & 100.000
\end{tabular}

31.12.2019
642 Faiz Gelirleri
102 Bankalar

Etkin faiz fark kaydı

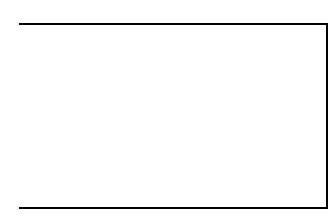

$10.000|10 . .000|$

31.12.2019

115 Banka Vadeli Mevduat 102 Bankalar

3-12 ay vadeli mevduatın aktarma kaydı

31.12.2019

642 Faiz Gelirleri

660 Mevduat Faiz Gelirleri

$90.000 \quad 90.000 \mid$

\begin{tabular}{l|l}
790.000 & 790.000
\end{tabular}

Döneme isabet eden faiz tahakkuku

-10.000 TL faiz, indirilebilir geçici fark olarak Ertelenmiş vergi varlığı ve sürdürülen faaliyetlerden ertelenmiş vergi geliri yaratacaktır.

3- Verilere göre VUK kaydı aşağıdaki gibidir.

31.12.2019

\begin{tabular}{|c|c|}
\hline $\begin{array}{c}101 \text { Alınan Çekler } \\
600 \text { Yurt İçi Satışlar }\end{array}$ & 2.000 .000 \\
KDV hariç yurt içi satış kaydı & 2.000 .000
\end{tabular}

TFRS' ye dönüşümde satışların peşin değere indirgenmesi ve alacakların itfa edilmiş maliyet bedeline getirilmesi veride yer alan 300.000 TL vade farkı (370 gün) dikkate alınarak aşağıdaki düzeltme kaydı ile sağlanır. 
31.12.2019

600 Yurt İçi Satışlar

128 Ert. Vade Farkı Gel.

Satışlardan vade farklarının tenzil kaydı

\begin{tabular}{l|l}
300.000 & 300.000
\end{tabular}

300.000 TL vade fark1, indirilebilir geçici farktır. Ertelenmiş vergi varlığı ve sürdürülen faaliyetlerden ertelenmiş vergi geliri yaratacaktır. Ayrıca 101 Çekler hesabı vadeli çek olması nedeniyle 122 Alınan İleri tarihli Çekler hesabına aktarılacaktır.

31.12.2019

222 Alınan İleri tarihli Çekler

101 Alınan Çekler

2.000 .000

2.000 .000

Vadeli çeklerin aktarma kaydı

4- Verilere göre VUK kaydı aşağıdaki gibidir.

31.12.2019

\begin{tabular}{|c|c|c|}
\hline $\begin{array}{c}153 \text { Ticari Mallar } \\
103 \text { Verilen Çekler }\end{array}$ & 700.000 & 700.000 \\
Ticari mal alımı kaydı & &
\end{tabular}

TFRS' ye dönüşümde ticari malların peşin değere indirgenmesi ve borçların itfa edilmiş maliyet bedeline getirilmesi veride yer alan 100.000 TL vade fark1 (370 gün) dikkate alınarak aşağıdaki düzeltme kaydı ile sağlanır.

31.12.2019

328 Ertelenmiş Vade Farkı Giderleri

153 Ticari Mallar

Alışlardan vade farklarının tenzil kaydı

\begin{tabular}{l|l}
100.000 & \\
&
\end{tabular} \mid

100.000 TL vade farkı indirilebilir geçici farktır. Ancak işlemde sonuç hesapları değil, sadece bilanço hesapları etkilendiğinden ertelenmiş vergi ve sürdürülen faaliyetlerden ertelenmiş vergi hesapları cari dönemde doğmamaktadır. Ayrıca 103 Verilen Çekler hesabı vadeli çek olması nedeniyle 322 Verilen İleri tarihli Çekler hesabına aktarılacaktır.

31.12.2019

103 Verilen Çekler

422 Ver. İleri Tar. Çekler

700.000

700.000

Vadeli çeklerin aktarma kaydı 
5- 108 Diğer hazır değerler kredi kartlarından alacaklar toplam 500.000 TL olarak TFRS ye uygun hesap planında 104 Kredi Kartıyla Yapılan Satışlardan Nakit Benzeri Nitelikteki Alacaklar hesabına aktarılmaktadır. Söz konusu alacaklar yurt içi satışlardan kaynaklanmaktadır, BOBİ FRS' de 12 vadeden kısa olması nedeniyle faiz (Kredi kartı alacaklarının içerisinde 20.000 TL gerçekleşmemiş faiz ) ayrıştırılmamaktadır.

31.12.2019

104 Kr. Kart. Yap. Sat.Nakit Alacaklar

108 Diğer Hazır Değerler

Vadeli çeklerin aktarma kaydı

500.000

500.000

6-Şirket portföyünde tahvil ve bono bulunmadığından herhangi bir kayıt söz konusu değildir.

7) Şirket dönem sonunda 6 ay sonrası için 8 TL'den 100.000 Euro forward kontrata girmiştir. Başlangıç maliyeti bulunmamaktadır. Başlangıç maliyeti olmayan türev araçlar dipnotlarda açıklanacak olup, sözleşme tarihinde kayıt gerektirmemektedir.

8) Şirket portföyünde uzun vadede değer artış kazancı sağlamak üzere $300.000 \mathrm{TL}$ tutarında hisse senedi BOBİ FRS' de gerçeğe uygun değer 800.000 TL olarak aşağıdaki gibi kayit alacaktır.

31.12.2019

200 GUD Farkı Kar Zarara Yan. Fin. Yat.

110 Hisse Senetleri

646 Ort. Yat.dan Sağl.Gel.ve Kazançlar

Hisse senetlerinin gud değerlemesi

800.000

300.000

500.000

500.000 TL vade fark1 vergiye tabi geçici farktır. Ertelenmiş vergi yükümlülügü ve sürdürülen faaliyetlerden ertelenmiş vergi gideri yaratacaktır.

9) Şirketin dava ve icra safhasında olmaması nedeniyle VUK kapsamında şüpheli alacak karşılığı ayırmadığı aşağıdaki gibidir.

31.12.2019

128 Şüpheli Ticari Alacaklar

120 Alıcilar

Şüpheli ticari alacaklara kayıt

1.000 .000

BOBİ FRS uyarınca iflas olasılığı bulunan borçlulardan olan alacaklara karşı1ık kaydı aşağıdaki gibi olacaktır. 
31.12.2019

127 Şüpheli Ticari Alacaklar

128 Şüp. Ticari Alacaklar

TFRS'ye uygun hesap planı kayıt

31.12 .2019

651 Karşıllk Giderleri

300.000

300.000

TFRS'ye uygun hesap planı kayıt

300.000 TL indirilebilir geçici fark olup, ertelenmiş vergi varlığ 1 ve sürdürülen faaliyetlerden ertelenmiş vergi geliri yaratmaktadır. olacaktır.

10) Şirketin alacaklarını yaşlandırması nedeniyle karşılık kayıtları aşağıdaki gibi

31.12.2019

127 Şüpheli Ticari Alacaklar

120 Şüp. Ticari Alacaklar

TFRS'ye uygun hesap planı gereği kayıt

\begin{tabular}{l|l}
200.000 & 200.000
\end{tabular}

31.12.2019

651 Karşıllk Giderleri

200.000

129 Tic.Al.Değ.Düş. Karş.

TFRS'ye uygun hesap planı gereği kayıt

200.000 TL indirilebilir geçici fark olup, ertelenmiş vergi varlığı ve sürdürülen faaliyetlerden ertelenmiş vergi geliri yaratmaktadır.

11- Garanti gider karşılıkları BOBİ FRS için kayıt aşağıdaki gibi olacaktır. VUK için kayıt söz konusu değildir.

31.12.2019

\section{Pazarlama Satış Dağıtım Giderleri}

475 Garanti Karşılıkları

700.000

700.000

Garanti gider karşılık kaydı

700.000 TL indirilebilir geçici fark olup, ertelenmiş vergi varlığ 1 ve sürdürülen faaliyetlerden ertelenmiş vergi geliri yaratmaktadır. 
12) Kıdem tazminat karşılıkları ve birikmiş izin karşılıkları için BOBİ FRS kayıtları aşağıdaki gibi olacaktır. VUK için kayıt söz konusu değildir.

31.12.2019

770 Genel Yönetim Giderleri

472 Kıd.Tazm. Karşılıkları

Kıdem tazminat karşılık kaydı

500.000 TL indirilebilir geçici fark olup, ertelenmiş vergi varlığı ve sürdürülen faaliyetlerden ertelenmiş vergi geliri yaratmaktadır.

31.12.2019

770 Genel Yönetim Giderleri

473 Çal.Sağ. Diğ. Fay. K.

100.000

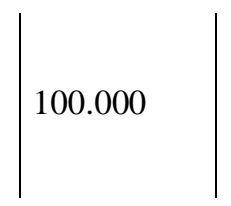

Birikmiş izin karşılık kaydı

100.000 TL indirilebilir geçici fark olup, ertelenmiş vergi varlığı ve sürdürülen faaliyetlerden ertelenmiş vergi geliri yaratmaktadır.

13- Verilere göre VUK kaydı aşağıdaki gibidir.

31.12.2019

\begin{tabular}{c}
120 Alıcılar \\
KDV hariç yurt içi satış kaydı İçi Satışlar \\
\hline
\end{tabular}

10.000 .000

10.000 .000

Satışların peşin değere indirgenmesi ve alacakların itfa edilmiş maliyet bedeline getirilmesi veride yer alan 1.000.000 TL vade fark1 (370 gün) dikkate alınarak aşağıdaki düzeltme kaydı ile sağlanır.

31.12.2019

$\mid$\begin{tabular}{c|c|}
\hline $\begin{array}{c}600 \text { Yurt İçi Satışlar } \\
128 \text { Ert.Vade Far. Gelirleri } \\
\text { Satışlardan vade farklarının tenzil kaydı }\end{array}$ & 1.000 .000 \\
\hline
\end{tabular}

1.000.000 TL vade farkı indirilebilir geçici farktır. Ertelenmiş vergi varlığı ve sürdürülen faaliyetlerden ertelenmiş vergi geliri yaratacaktır. 
14- Verilere göre VUK kaydı aşağıdaki gibidir.

31.12 .2019
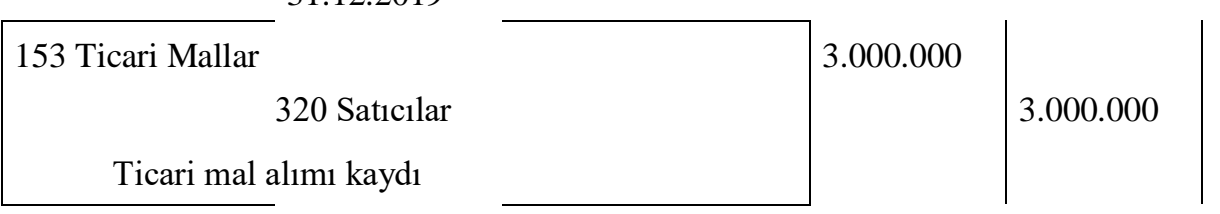

Ticari malların peşin değere indirgenmesi ve borçların itfa edilmiş maliyet bedeline getirilmesi veride yer alan 750.000 TL vade farkı (370 gün) dikkate alınarak aşağıdaki düzeltme kaydı ile sağlanır.

$$
\text { 31.12.2019 }
$$

328 Ertelenmiş Vade Farkı Giderleri

153 Ticari Mallar

Alışlardan vade farklarının tenzil kaydı

\begin{tabular}{l|l}
750.000 & \\
&
\end{tabular}

750.000 TL vade farkı indirilebilir geçici farktır. Ancak işlemde bilanço hesapları etkilendiğinden ertelenmiş vergi ve sürdürülen faaliyetlerden ertelenmiş vergi hesapları cari dönemde doğmamaktadır.

15- VUK koşulları sağlanmadığından stok değer düşüklüğü karşıllğı ayrılmamış olup, FRS' ye uygun hesap planına göre karşılık kaydı aşağıdaki gibi olacaktır.

$$
31.12 .2019
$$

626 Stok Değer Düş. Karşıllık Giderleri ( - )

158 Stok Değ. Düş. Karş.(-)

100.000

100.000

Stok değer düşüklüğü karşılık kaydı

100.000 TL indirilebilir geçici fark olup, ertelenmiş vergi varlığı ve sürdürülen faaliyetlerden ertelenmiş vergi geliri yaratmaktadır.

16- BOBİ FRS için satış amaçlı elde tutulan duran varlık sınıfı kullanılmamaktadır. $\mathrm{Bu}$ nedenle binalar için satış kararı alınsa da satış amaçlı olarak sınıflandırılmaz. Öte yandan kiraya verilen kısım (2.000.000 TL) için yatırım amaçlı gayrimenkuller hesabına aktarma yapılacaktır. Yönetim kurulu değerleme nedeniyle yüksek maliyete katlanmak istemediğinden 246 Maliyet ile Ölçülen Yatırım Amaçlı Gayrimenkuller hesabı kullanılacaktır. 
31.12.2019

\begin{tabular}{|c|c|}
$\begin{array}{c}\text { 246 Maliyet ile Ölç. Yat. Ama.Gayrimenkuller } \\
\text { 252 Binalar }\end{array}$ & 2.000 .000 \\
Maliyet ile YAG değerleme kaydı & 2.000 .000
\end{tabular}

17- Yatırım amaçlı arazi ve arsalar yeniden değerleme modeli seçildiğinden BOBİ FRS' de gerçeğe uygun değerle değerlenen yatırım amaçlı gayrimenkullere aktarılacaktır.

31.12.2019

245 GUD ile Ölç. Yat. Amaç. Gayrimenkuller

250 Arsa ve Araziler

Arazi ve arsaların GUD değerleme kaydı

31.12.2019

245 GUD ile Ölçülen YA. Gayrimenkuller

647 YA. Gay. Gel.ve Karlar

GUD değerlemesi farkı

\begin{tabular}{l|l}
3.000 .000 & 3.000 .000
\end{tabular}

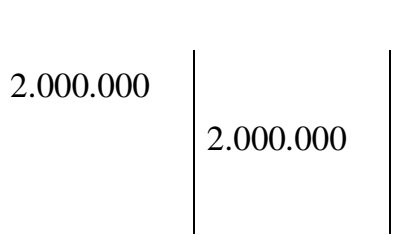

2.000.000 TL vergiye tabi geçici fark olup ertelenmiş vergi yükümlülüğü ve sürdürülen faaliyetlerden ertelenmiş vergi gideri doğmaktadır.

18- Maddi duran varlıklarda yer alan 1.000.000 TL değerindeki binaların arsa payı BOBİ FRS' de arazi ve arsalara aktarılmaktadır.

31.12.2019

250 Arazi ve Arsalar

252 Binalar

Bina arsa değ. arazi ve arsalar aktarımı

19) Makinelerin defter değeri (1.000.000-600.000=) 400.000 TL'dir. Geri kazanılabilir tutar, satış maliyeti düşülmüş gerçeğe uygun değerden (350.000 TL) kullanım değeri (300.000 TL) düşüldükten sonra kalan değerden büyük olanıdır. Buna göre geri kazanılabilir tutar $350.000 \mathrm{TL}$ ve değer düşüklüğü $(400.000-350.000=) \quad 50.000 \quad \mathrm{TL}$ olarak hesaplanmaktadır. Bu tutar üzerinden BOBİ FRS' de karşılık kaydı aşağıdaki gibi olacaktır.

31.12.2019

651 Karşılık Giderleri

257 MDV Değ.Düş. Karş.

50.000

50.000

Makinelerin değer düş. karşılık kaydı 
50.000 TL indirilebilir geçici fark olup, ertelenmiş vergi varlığı ve sürdürülen faaliyetlerden ertelenmiş vergi geliri yaratmaktadır.

20) Demirbaşlar için yeniden değerleme modeli seçildiğinden değer artışı öz kaynaklara kaydedilir. Kurumlar Vergisi oranı \% 20 kabul edilmiştir. İstisna koşullarının sağlanamadığı varsayılmaktadır.

31.12.2019

255 Demirbaşlar

551 MDV Yen.Değ.Artış1

200.000

200.000

Demirbaşlardaki değer artış kaydı

31.12.2019

559 Öz Kay.Kaydedilen Gelirlere Ait Vergiler

489 Ertelenmiş Vergi Yük.

40.000

40.000

Değer artışının ertelenmiş vergi kaydı

21- Arsa payına amortisman ayrılamayacağından BOBİ FRS' de VUK amortisman iptali ters kayıtla yapılır. Kalıcı fark olduğu için ertelenmiş vergi kaydı gerekmemektedir.

31.12.2019

257 Birikmiş Amortismanlar

770 Genel Yönetim Giderleri

Arsa payına ait amortisman iptal kaydı

12.000

12.000

22- Verilere göre VUK kayıtları aşağıdaki gibidir.

31.12.2019

262 Kuruluş ve Örgütlenme Giderleri

102 Bankalar

Kuruluş giderlerinin bankadan ödenmesi

300.000

300.000

31.12.2019

770 Genel Yönetim Giderleri

268 Birikmiş Amortismanlar

Kuruluş ve örgütlenme giderlerinin itfası

60.000

60.000

BOBİ FRS' ye göre kuruluş ve örgütlenme giderleri aktifleştirilmeyeceğinden aşağıdaki kayıt yapılacaktır. 
31.12.2019

770 Genel Yönetim giderleri

268 Birikmiş Amortismanlar

262 Kur. ve Örg. Giderleri

Kuruluş ve örgütlenme gider kaydı

\begin{tabular}{r|r}
240.000 & \\
60.000 & 300.000
\end{tabular}

240.000 TL indirilebilir geçici fark olup, ertelenmiş vergi varlığ 1 ve sürdürülen faaliyetlerden ertelenmiş vergi geliri yaratmaktadır.

23- VUK' a göre özel maliyetin itfa kaydı aşağıdaki gibidir.

31.12.2019

770 Genel Yönetim Giderleri

268 Birikmiş Amortismanlar

14.000

14.000

Özel maliyetlerin itfa kaydı

Özel maliyet hesabı BOBİ FRS' ye uygun değildir, bu hesap yerine ilgili varlık hesabı kullanılacaktır. Ayrıca amortismanlar maddi duran varlıklar grubu içerisinde ayrılacaktır.

31.12.2019

255 Demirbaşlar

31.12 .2019

264 Özel Maliyeler

Özel maliyetlerin demirbaş kaydı

\begin{tabular}{l|l}
70.000 & \\
&
\end{tabular}

31.12..2019

268 Birikmiş Amortismanlar

257 Birikmiş Amortismanlar

14.000

14.000

Demirbaşların İtfası düzeltme kaydı

Amortisman süresi eşit kabul edildiğinden ertelenmiş vergi doğmamaktadır.

24- VUK için ayrılan amortisman BOBİ FRS için 100.000 TL azaltılacaktır.

31.12.2019

257 Birikmiş Amortismanlar

100.000

770 Genel Yön. Giderleri

100.000

Demirbaşların İtfası düzeltme kaydı 
100.000 TL vergiye tabi geçici fark olup ertelenmiş vergi yükümlülüğü ve sürdürülen faaliyetlerden ertelenmiş vergi gideri doğmaktadır.

25- Satışların içerisinde yer alan 2.000.000 TL vade farkı (370 gün) 3. Kayıttan 300.000 TL ve 13. Kayıttan 1.000.000 TL olmak üzere toplam 1.300.000 TL ertelenmiş vade fark1 gelirleri tenzil edildikten sonra kalan (2.000.000-1.300.000=) 700.000 TL vade fark1 (370 gün) geliri olarak kar zarara yansıtılırken satışlar bu tutar kadar azaltılır.

31.12.2019

\begin{tabular}{|c|c|}
\hline 600 Yurt İçi Satışlar & 700.000 \\
640 Vade Farkı Gelirleri & 700.000 \\
Vade farklarının satışlardan tenzili &
\end{tabular}

Her iki kalem kar ve zarar tablosu kalemi olduğundan ertelenmiş vergi doğmamaktadır.

26-Satılan ticari malların maliyeti içerisinde yer alan 1.400.000 TL vade farkı (370 gün) 4. Kayıttan 100.000 TL ve 14. Kayıttan 750.000 TL olmak üzere toplam 850.000 TL ertelenmiş vade fark1 giderleri tenzil edildikten sonra kalan $(1.400 .000-850.000=) 550.000 \mathrm{TL}$ vade farkı (370 gün) gideri olarak kar zarara yansitılırken satılan ticari malların maliyeti bu tutar kadar azaltılır.

31.12..2019

650 Vade Fark1 Giderleri

621 Sat. Tic. Mal. Maliyeti

Vade farklarının satışlardan tenzili

Her iki kalem kar ve zarar tablosu kalemi olduğundan ertelenmiş vergi doğmamaktadır.

27- Alınan 15.000.000 TL banka kredisi, banka kredileri hesabına kaydedilmiştir.

\section{Hesaplanması:}

Ertelenmiș Vergi Varlıkları ve Ertelenmiș Vergi Yükümlülüklerinin

Yukarıdaki kayıtlar sonucunda İndirilebilir Geçici Farklar (İGF) ve Ertelenmiş Vergi Varlıkları (EVV) Tablosu aşağıdaki gibidir (Kurumlar Vergisi Oranı \% 20 kabul edilmektedir).

\begin{tabular}{|c|r|r|l|}
\hline $\begin{array}{c}\text { Yevmiye } \\
\text { No }\end{array}$ & IGF (TL) & $\begin{array}{c}\text { EVV ve Vergi } \\
\text { Geliri (TL) }\end{array}$ & \multicolumn{1}{|c|}{ Açıklamalar } \\
\hline 2 & 10.000 & 2.000 & Vadeli mevduat etkin faiz fark1 \\
\hline 3 & 300.000 & 60.000 & Satışlar/Ertelenmiş Vade Fark1 Gelirleri \\
\hline 9 & 300.000 & 60.000 & Konkordato hazırlığı karşılık giderleri \\
\hline 10 & 200.000 & 40.000 & Yaşlandırma nedeniyle karşılık giderleri \\
\hline 11 & 700.000 & 140.000 & Garanti gider karşılıkları \\
\hline
\end{tabular}




\begin{tabular}{|c|r|r|l|}
\hline 12 & 500.000 & 100.000 & Kıdem tazminat karş1lıkları \\
\hline 12 & 100.000 & 20.000 & İzin gider karş1lıkları \\
\hline 13 & 1.000 .000 & 200.000 & Satışlar Ertelenmiş Vade Farkı Geliri \\
\hline 15 & 100.000 & 20.000 & Stok değer düşüklüğü karş1lıkları \\
\hline 19 & 50.000 & 10.000 & Makineler değer düşüklüğü zararı \\
\hline 22 & 240.000 & 48.000 & Kuruluş ve örgütlenme giderleri \\
\hline Toplam & $\mathbf{3 . 5 0 0 . 0 0 0}$ & $\mathbf{7 0 0 . 0 0 0}$ & \\
\hline
\end{tabular}

Yukarıdaki kayıtlar sonucunda Vergiye Tabi Geçici Farklar (VTGF) ve Ertelenmiş Vergi Yükümlülükleri (EVY) Tablosu aşağıdaki gibidir (Kurumlar Vergisi Oranı \% 20 kabul edilmektedir).

\begin{tabular}{|c|r|r|l|}
\hline $\begin{array}{c}\text { Yevmiye } \\
\text { No }\end{array}$ & VTGF (TL) & $\begin{array}{c}\text { EVY ve Vergi } \\
\text { Gideri (TL) }\end{array}$ & \multicolumn{1}{c|}{ Açıklamalar } \\
\hline 8 & 500.000 & 100.000 & Hisse senetleri gerçeğe uygun değerleme \\
\hline 17 & 2.000 .000 & 400.000 & Yatırım amaçlı gayrimenkuller değer artışı \\
\hline 24 & 100.000 & 20.000 & Amortisman farkları \\
\hline Toplam & $\mathbf{2 . 6 0 0 . 0 0 0}$ & $\mathbf{5 2 0 . 0 0 0}$ & \\
\hline
\end{tabular}

Yukarıdaki hesaplamalara göre ertelenmiş vergi kayıtları aşağıdaki gibidir. Ayrıca 20. Kayıttan Maddi Duran Varlıklar Yeniden Değerleme Artışlarından gelen 40.000 TL öz kaynaklarda raporlanan vergi gider etkisi bulunmaktadır. Bununla birlikte ertelenmiş vergi yükümlülüğü $(520.000+40.000=) 560.000 \mathrm{TL}$ olarak hesaplanmaktadır.

31.12.2019

289 Ertelenmiş Vergi Varlıkları

692 Sür. Fa.EV Gel./Gid.E.

700.000

700.000

İndirilebilir geçici farkların kaydı

31.12.2019

692 Sür. Fa. EV Gel./Gid. E.(+/-)

489 Ert. Ver. Yükümlülüğü

520.000

Vergiye tabi geçici farkların kaydı

\begin{tabular}{|l|r|r|}
\hline BİRLIK A.Ş. BOBİ FRS BİLANÇOSU & & \\
\hline 1 DÖNEN VARLIKLAR & & $\mathbf{2 0 . 5 6 0 . 0 0 0}$ \\
\hline 10 NAKİT VE NAKİT BENZERLERİ & 100.000 & 600.000 \\
\hline 100 Nakit Kasası & 500.000 & \\
\hline 104 Kredi Kartı Satışlardan Nakit Benzeri Nit. Alacaklar & & 1.590 .000 \\
\hline 11 (110-118) FİNANSAL YATIRIMLAR & 800.000 & \\
\hline 110 GUD Fark1 Kar veya Zarara Yansıtılan Fin. Yatırımlar & 790.000 & \\
\hline 115 Bankalardaki Vadeli Mevduat & & 16.200 .000 \\
\hline 12 TíCARİ ALACAKLAR & 9.800 .000 & \\
\hline 120 Müşterilerden Alacaklar & 5.000 .000 & \\
\hline 121 Alacak Senetleri & & \\
\hline
\end{tabular}




\begin{tabular}{|l|r|r|}
\hline 122 Alınan İleri Tarihli Çekler & 2.000 .000 & \\
\hline 127 Şüpheli Ticari Alacaklar & 1.200 .000 & \\
\hline 128 Ertelenmiş Vade Farkı Gelirleri (-) & $(1.300 .000)$ & \\
\hline 129 Ticari Alacaklar Değer Düşüklüğ̈̈ Karşıllıları (-) & & 2.050 .000 \\
\hline 15 STOKLAR & 2.150 .000 & \\
\hline 153 Ticari Mallar & $(100.000)$ & \\
\hline 158 Stok Değer Düşüklüğü Karşılıkları (-) & & 120.000 \\
\hline 19 (190- 195) DİGER DÖNEN VARLIKLAR & & $\mathbf{1 4 . 3 9 8 . 0 0 0}$ \\
\hline 190 Devreden KDV & & 7.000 .000 \\
\hline 2 DURAN VARLIKLAR & 5.000 .000 & \\
\hline 24 (245-249) YATIRIM AMAÇLI GAYRIMENKULLER & 2.000 .000 & \\
\hline 245 GUD İle Ölçülen Yatırım Amaçlı Gayrimenkuller & & 6.618 .000 \\
\hline 246 Maliyetle Ölçülen Yatırım Amaçlı Gayrimenkuller & 600.000 & \\
\hline 25 MADDİ DURAN VARLIKLAR & 4.400 .000 & \\
\hline 250 Arazi ve Arsalar & 1.000 .000 & \\
\hline 252 Binalar & 500.000 & \\
\hline 253 Tesis, Makine ve Cihazlar & 570.000 & \\
\hline 254 Taşıtlar & $(50.000)$ & \\
\hline 255 Demirbaşlar & $(402.000)$ & \\
\hline 257 Maddi Duran Varlıklar Değer Düşüklüğü Karşılıkları (-) & & \\
\hline 258 Birikmiş Amortismanlar (-) & 100.000 & \\
\hline 26 ŞEREFIYYE VE MADDİ OLM. DURAN VARLIKLAR & & \\
\hline 264 Geliştirme Maliyetleri & & \\
\hline 268 Birikmiş Amortismanlar (-) & & $\mathbf{3 4 . 9 5 8 . 0 0 0}$ \\
\hline 28 (289) ERTELENMIŞ VERGI VARLIĞI & & \\
\hline 289 Ertelenmiş Vergi Varlığı & & \\
\hline TOPLAM VARLIKLAR & & \\
\hline
\end{tabular}

\begin{tabular}{|c|c|c|}
\hline 3 KISA VADELİ YÜKÜMLÜLÜKLER & & 16.470 .000 \\
\hline 30 (300-308) FINANSAL YÜKÜMLÜLÜKLER & & 15.000 .000 \\
\hline 300 Banka Kredileri & 15.000 .000 & \\
\hline 32 TİCARİ BORCCLAR & & 1.450 .000 \\
\hline 320 Satıcilar & 1.600 .000 & \\
\hline 322 Verilen İleri Tarihli Çekler & 700.000 & \\
\hline 328 Ertelenmiș Vade Farkı Giderleri (-) & $(850.000)$ & \\
\hline 36 ÖDENECEK VERGİ VE DİĞ.YASAL YÜK. & & 160.000 \\
\hline 360 Gelir Üzerinden Alınan Vergiler & 100.000 & \\
\hline 365 Ödenecek Sosyal Güvenlik Kesintileri & 60.000 & \\
\hline 37 (370-371)DÖN.KARI VER.VE DİĞ. YAS. YÜK. KARȘ. & & $(140.000)$ \\
\hline 370 Dönem Karı Vergi ve Diğer Yasal Yük. Karşılıkları & 60.000 & \\
\hline $\begin{array}{l}371 \text { Dönem Karının Peşin Ödenen Vergi ve Diğer Yasal Yükümlülükleri } \\
\text { (-) (Ödenen Geçici Vergi) }\end{array}$ & $(200.000)$ & \\
\hline 4 UZUN VADELİ YÜKÜMLÜLÜKLER & & 1.860 .000 \\
\hline 47 KARŞILIKLAR & & 1.300 .000 \\
\hline 472 Kıdem Tazminatı Karşılıkları & 500.000 & \\
\hline 473 Çalışanlara Sağlanacak Diğer Faydalara İlişkin Karşılıklar & 100.000 & \\
\hline 475 Garanti Karşılıkları & 700.000 & \\
\hline 48 (489) ERTELENMİS VERGİ YÜKÜMLÜLÜĞÜ & & 560.000 \\
\hline 489 Ertelenmiş Vergi Yükümlülüğü & 560.000 & \\
\hline 5 ÖZKAYNAKLAR & & 16.628 .000 \\
\hline 50 ÖDENMİŞ SERMAYE & & 15.836 .000 \\
\hline 500 Sermaye & 15.836 .000 & \\
\hline $\begin{array}{l}55 \text { KAR ZARARDA YEN. SINIFLANDIRILMAYACAK ÖZK.I } \\
\text { KAYD. BİIKMISS GELIRLER (GIDERLER) }\end{array}$ & & 160.000 \\
\hline
\end{tabular}




\begin{tabular}{|l|r|r|}
\hline 551 Maddi Duran Varlıklar Yeniden Değerleme Artışları & 200.000 & \\
\hline $\begin{array}{l}\text { 559 Kar veya Zararda Yeniden Sınıflandırılmayacak Özk.da Kaydedilen } \\
\text { Birikmiş Gelirlere (Giderlere) İlişk.Vergiler }( \pm)\end{array}$ & $(40.000)$ & \\
\hline 59 DÖNEM NET KARI (ZARARI) & & 632.000 \\
\hline 590 Dönem Net Karı & 632.000 & \\
\hline TOPLAM KAYNAKLAR & & $\mathbf{3 4 . 9 5 8 . 0 0 0}$ \\
\hline
\end{tabular}

\begin{tabular}{|c|c|c|}
\hline BİRLIK A.Ş. BOBİ FRS KAR VEYA ZARAR TABLOSU & & \\
\hline 6 KAR VEYA ZARAR TABLOSU HESAPLARI & & \\
\hline 60 BRÜT SATIŞ HASILATI & & 8.000 .000 \\
\hline 600 Yurtiçi Satışlar & 8.000 .000 & \\
\hline 62 SATIŞLARIN MALIYYETLERİ (-) & & $(6.550 .000)$ \\
\hline 621 Satılan Ticari Mallar Maliyeti (-) & $(6.450 .000)$ & \\
\hline 626 Stok Değer Düşüklüğü Karşılık Giderleri (-) & $(100.000)$ & \\
\hline 63 ESAS FAALIYYT DÖNEM GİDERLERİ (-) & & $(2.128 .000)$ \\
\hline 631 Pazarlama, Satış ve Dağıtım Giderleri (-) & $(1.200 .000)$ & \\
\hline 632 Genel Yönetim Giderleri (-) & $(928.000)$ & \\
\hline $\begin{array}{lrlllll}64 & (640-644) & \text { ESAS } & \text { FAALIYETLERDEN } & \text { DİĞER } & \text { GELİR } & \text { VE } \\
\text { KAZANÇLAR } & & & & & \end{array}$ & & 700.000 \\
\hline $\begin{array}{l}640 \text { Esas Faaliyet Alacaklarına İlişkin Vade Farkı Gelirleri ve Esas } \\
\text { Faaliyetlerle İlgili Kur Farkı Kazançları }\end{array}$ & 700.000 & \\
\hline 64 (645-649) DİĞER FAALIYYETLERDEN GELİR VE KAZANÇLAR & & 3.500 .000 \\
\hline 646 Ortaklıklardaki Yatırımlardan Sağlanan Gelir ve Kazançlar & 1.500 .000 & \\
\hline 647 Yatırım Amaçlı Gayrimenkullerden Elde Edilen Gelir ve Kazançlar & 2.000 .000 & \\
\hline 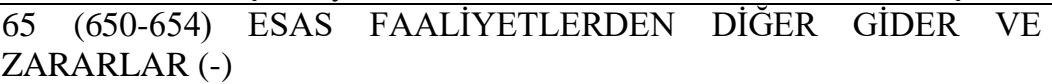 & & $(1.100 .000)$ \\
\hline $\begin{array}{l}650 \text { Ticari Borçlara İlişkin Vade Farkı Giderleri ve Esas Faaliyetlerle İlgili } \\
\text { Kur Farkı Zararları (-) }\end{array}$ & & 550.000 \\
\hline $\begin{array}{l}\text { 651 Esas faaliyet Alacaklarına İlişkin Değer Düşüklüğü Karşılık Giderleri } \\
\text { ( - ) }\end{array}$ & $(550.000)$ & \\
\hline 65 (655-659) DİĞER FAALIYYETLERDEN GİDER VE ZARARLAR & & $(2.000 .000)$ \\
\hline 659 Diğer Faaliyetlerden Çeşitli Gider ve Zararlar(-) & $(2.000 .000)$ & \\
\hline 66 FINANSAL GELİRLER & & 90.000 \\
\hline 660 Mevduat Faiz Gelirleri & $(90.000)$ & \\
\hline 69 DÖNEM NET KARI VEYA ZARARI & & 632.000 \\
\hline 690 Sürdürülen Faaliyetler Dönem Karı veya Zararı & 512.000 & \\
\hline 691 Sürdürülen Faaliyetler Dönem Karı Yasal Vergi Gideri (-) & $(60.000)$ & \\
\hline $\begin{array}{l}692 \text { Sürdürülen Faaliyetler Ertelenmiş Vergi Gelir - Gider Etkisi }( \pm) \\
(700.000-520.000=)\end{array}$ & 180.000 & \\
\hline 693 Sürdürülen Faaliyetler Dönem Net Kar1 veya Zararı & 632.000 & \\
\hline
\end{tabular}

Dönem sonu BOBİ FRS kapanış kaydında 693 Sürdürülen Faaliyetler Dönem Net Karı veya Zararı hesabına 632.000 TL borç, 590 Dönem Net Kar Zararı hesabına 632.000 TL alacak kaydedilmek suretiyle dönem kar zararının bilançoya aktarılmasına dair kapanış kaydı yap1lacaktır.

\section{SONUÇ}

Bağımsız denetime tabi firmalar tarafindan 01.01.2018 tarihinden itibaren Büyük ve Orta Ölçekli İşletmeler İçin Finansal Raporlama Standartlarının uygulanma zorunluluğu işletmeler için önemli bir gereksinimi beraberinde getirmektedir. Bilindiği üzere Türkiye'de öteden beri ağırlıklı olarak vergi muhasebesi uygulanmaktadır ve vergi mevzuatına göre 
işletmeler tarafından verilmesi gereken çok sayıda vergi beyannamesi (KDV, Muhtasar, Geçici Vergi, Kurumlar Vergisi, Gelir Vergisi) bulunmaktadır. Söz konusu beyannamelerin zamanında verilmemesi veya noksan bildirilmesi cezalı vergi tarhiyatı sonucunu doğurduğundan vergi muhasebesi tutulması VUK Madde 271'e göre yasal bir zorunluluktur. Maliye Bakanlığ 1 bu konudaki görüşünü muhafaza etmekte ve Vergi Usul Kanununa göre (VUK Madde 171) mükellefler yasal defter ve kayıtları; vergi uygulaması bakımından mükellefin vergi ile ilgili servet, sermaye ve hesap durumunu tespit etmek; vergi ile ilgili faaliyet ve hesap neticelerini tespit etmek; vergi ile ilgili muameleleri belli etmek; mükellefin vergi karşısındaki durumunu hesap üzerinden kontrol etmek ve incelemek; mükellefin hesap ve kayıtlarının yardımıyla üçüncü şahısların vergi karşısındaki durumlarını (emanet mahiyetindeki değerler dahil) kontrol etmek ve incelemek maksatlarını sağlayacak şekilde tutarlar.

TMS/TFRS veya BOBİ FRS' ye göre muhasebe kayıtları tutulmasından ve finansal tablolar çıkarılmasından sonra yasal mevzuatta yer alan vergisel maksatları sağlayacak kayıtların tutulması ve finansal tabloların çıkarılması ve vergi beyannamelerinin hazırlanması mümkün olmakla birlikte çok sayıda vergi beyannamesinin hemen her ay düzenlenecek olması önemli bir iş yükü gerektireceğinden ve olası hatalara dair yasal müeyyidelerinin çok ağır olması hususları da göz önüne alındığında bu çalışmada TMS/TFRS' den vergiye dönüştürme yöntemi yerine diğer bir yaklaşım olarak vergi mizanından BOBİ FRS' ye dönüştürme kayıtları ve neticesinde BOBİ FRS' ye uygun finansal tablolar çıkarılmasına dair bütünsel bir uygulama örneği ortaya konulmaya çalışılmıştır. Bütünsel uygulama örneği ile sistemin değerleme gününde vergi mizanından BOBİ FRS' ye dönüşümünün sağlanmasının çözüme yönelik bir yaklaşım olduğu, bu yöntemde vergi beyannamelerinin hazırlanmasının ilave çalışma gerektirmeyeceği, öte yandan bağımsız denetime tabi büyük ve orta boy işletmeler için finansal raporlama standartlarının gereği olan finansal tablolarının vergi mizanı çıkarıldıktan sonra işletmelerin yöneticileri, muhasebecileri ve bağımsız denetçilerinin koordinasyonu ve örnek uygulamada olduğu gibi ilave bilgilerin sağlanmasıyla düzenlenebileceği görülmektedir.

\section{KAYNAKLAR}

Büyük ve Orta Ölçekli İşletmeler İçin Finansal Raporlama Standartları, 29 Temmuz 2017 tarihli ve 30138 Sayılı Mükerrer Resmi Gazete

KGK, 25.12.2018 tarihinde yayınlanan Finansal Raporlama Standartlarına Uygun Hesap Planı Taslağ1 (https://www.kgk.gov.tr/ContentAssignmentDetail/2531/Finansal-RaporlamaStandartlar\%C4\%B1na-Uygun-Hesap-Plan\%C4\%B1-Taslag\%CC\%86\%C4\%B1)

213 Sayılı Vergi Usul Kanunu

Türkiye Muhasebe/ Finansal Raporlama Standartları (https://www.kgk.gov.t) 
